\title{
Perspectives of Health Service Providers on Barriers to Accessing Perinatal Mental Health Services in Karnataka, India: a Qualitative Study
}

\section{Debarati Mukherjee}

Indian Institutes of Public Health

Nolita Dolcy

Indian Institutes of Public Health

Daisy A John

Indian Institutes of Public Health

Maithili Karthik

Indian Institutes of Public Health

\section{Swapnil A Gadhave}

Indian Institutes of Public Health

Giridhara R Babu ( $\sim$ epigiridhar@gmail.com )

Indian Institutes of Public Health

\section{Research}

Keywords: perinatal depression, mental health, anxiety, health system, Manochaitanya, task shifting, stepped-care, scalable, Low and middle-income country, India

Posted Date: December 11th, 2020

DOI: https://doi.org/10.21203/rs.3.rs-122820/v1

License: (c) (i) This work is licensed under a Creative Commons Attribution 4.0 International License. Read Full License 


\section{Perspectives of health service providers on barriers to accessing}

2 perinatal mental health services in Karnataka, India: a qualitative

3 study

4

5 Debarati Mukherjee ${ }^{\#}$, Nolita Dolcy ${ }^{\#}$, Daisy A John, Maithili Karthik, Swapnil A Gadhave,

6 Giridhara R Babu*

7

8 Indian Institute of Public Health, Bengaluru Campus, Magadi Rd 1st cross, State Institute of

$9 \quad$ Health and Family Welfare premises, Bengaluru, Karnataka 560023

10

$11 \quad$ \#Joint first authors

12

$13 *$ *Correspondence: Giridhara R Babu (epigiridhar@gmail.com)

14

15 Number of Tables and Figures: 4 


\section{Abstract}

17 Background: Poor maternal mental health is a major public health concern since it adversely impacts both maternal and child health outcomes. This study aimed to document the barriers to utilizing perinatal mental health services in Karnataka, India, and to determine its relationship with risk factors of poor maternal mental health in this context.

Methods: Qualitative research methods using in-depth interviews were conducted on twenty-one local stakeholders who represented health service providers in various capacities: mental health specialists $(n=4)$, gynaecologists $(n=2)$, government officials from the Department of Health and Family Welfare $(n=2)$, and Department of Women and Child Development $(n=2)$, senior state consultant to United Nations Children's Fund $(\mathrm{n}=1)$, and frontline workers $(\mathrm{n}=10)$. Data were analysed using a thematic framework analysis approach.

27 Results: We identified multiple barriers to service utilization operating at the levels of the health system, community, family, and the individual. Health-system level barriers included lack of a universal screening mechanism, poor infrastructure, poor training of frontline workers on mental health issues, and inadequate time for counselling and treatment. Community-level barriers

31 included stigma and misconceptions, leading to a lack of social support. Family and individual

32 level barriers included the financial burden of availing services, lack of family and partner

33 support, and lack of empowerment and motivation in the woman to seek services. Family and

34 individual level barriers interacted with risk factors of poor maternal mental health. Based on this

35 evidence and drawing from the literature, we propose a contextualised, stepped-care model for

36 universal screening, detection, referral, and treatment of women with perinatal mental health

37 conditions for Karnataka that is integrated with the reproductive, maternal, and child health

$38(\mathrm{RMNCH})$ program in primary care settings. 
39 Conclusions: The framework developed in this study suggests that addressing the identified

40 barriers would potentially increase uptake of available services, create awareness about and

41 demand for high-quality mental health services, reduce the risk factors of poor maternal mental

42 health, and eventually improve our understanding of its true burden in the state of Karnataka.

43 This is essential for proper implementation, monitoring, and evaluation of programs relevant to

44 perinatal mental health.

45 Keywords: perinatal depression, mental health, anxiety, health system, Manochaitanya, task

46 shifting, stepped-care, scalable, Low and middle-income country, India 


\section{Background}

48 The health and development of a child are intrinsically linked to their mother's physical and

49 mental well-being (1,2). Poor maternal mental health can adversely impact a range of pregnancy,

50 birth, and child outcomes (3-5) such as higher risks of obstetric complications, preterm labour,

51 fetal growth restrictions, low birth weight of the baby, delayed initiation of breastfeeding, and

52 low quality of responsive caregiving (5). These, in turn, can lead to heightened irritability in the

53 child and reduced ability for emotion regulation (6), as well as impaired cognitive, motor, and

54 social development in the long term (7-9).

$5512 \%$ of women globally, and around $19 \%$ in developing countries, experience depression, and

56 anxiety in the perinatal period (10). According to recent studies, the prevalence of prenatal

57 depressive symptoms in Karnataka, the region of focus in this study, is an alarming 36.8\% (11),

58 with similar trends being reported for the capital city of Bengaluru (12). Given the current

59 burden and its adverse consequences on both mother and child, prevention, early detection, and

60 treatment are essential first steps towards achieving the Sustainable Development Goals (SDGs)

61 related to improving maternal and child health outcomes (13).

62 Although the need for maternal mental health services is high, the availability and accessibility

63 of these services severely fall short of the need, especially in low-resource settings (14). Multiple

64 factors are responsible for these lacunae. At the health-system level, important barriers include

65 the lack of trained manpower, poor infrastructure towards providing mental healthcare in

66 primary care settings, unlinked services leading to poor continuity of care, poorly defined

67 referral pathways, and resistance to decentralize services $(15,16)$. Similarly, provider-level

68 barriers such as the lack of training and supervision of medical staff on mental healthcare, a

69 baby-centered approach in perinatal care, and time constraints in providing quality service have 
70 been reported (15-17). Together, these factors have led to a failure to diagnose and treat upwards

71 of $90 \%$ of those who need mental healthcare in low- and middle-income countries (LMICS) (18-

72 20).

73 On the other hand, demand-side barriers including the lack of awareness about mental illnesses

74 and their potential for treatment, lack of family or partner support to seek care, the complicated

75 logistics of getting and attending an appointment, the financial burden of availing treatment, fear

76 and stigma associated with a diagnosis of a mental health condition, and the disadvantaged

77 position of women in communities, prevent women from seeking services even when they are

78 available (16,21). Low demand for services reduces the prioritization of service provision in

79 primary care settings $(22,23)$, leading to poor resource allocation towards mental healthcare

80 across decades $(24,25)$.

81 To address these multilevel barriers, a holistic approach is required to meet the end-goal of

82 providing universal, effective, and high-quality mental health services (26). Some countries have

83 taken a first step towards integrating perinatal mental health in primary care settings, providing

84 templates for the operationalization of this goal worldwide (27). To address system and provider-

85 level barriers, most of these templates follow a stepped-care approach, with mild to moderate

86 cases being counseled or treated by minimally trained non-specialists and only severe cases

87 being referred to specialists (28).

88 In India, Kerala was among the first states to launch a stepped-care approach to maternal mental

89 health through a program called "Amma Manasu" (mother's mind), which integrated mental

90 health screening and interventions within routine perinatal health programs (29). Similarly,

91 Karnataka's ambitious Manochaithanya ("empowering the mind") program, although not

92 exclusive to perinatal mental health, aims to provide mental healthcare services in primary care 
settings (30). With 100\% coverage in all districts, this "near to home service" has largely bridged the availability and accessibility issues (31). A few additional initiatives specifically designed to promote and protect perinatal mental health is in the pipeline $(32,33)$ - making Karnataka one of the frontrunners in designing universal programs for comprehensive care of perinatal mental health across all districts in the state.

While these novel initiatives are being rolled out, it is imperative to take stock of potential barriers that may be specific to this region for the uptake of these services. This forward-looking approach will help ensure that these factors are addressed from the outset and proposed solutions to be integrated within the program's design. To this end, this study aimed to identify potential barriers to the effective utilization of perinatal mental health services in the state of Karnataka, India, from the perspective of a wide range of healthcare providers (mental health professionals, government officials leading maternal and child health programs, gynecologists, and frontline workers such as the Accredited Social Health Activists (ASHA), Anganwadi workers (AWW), and Auxiliary Nurse \& Midwives (ANM). Qualitative research methods with a framework analysis approach were used to identify barriers at the health system, community, family, and individual level. Additionally, since family-level factors such as domestic violence, lack of partner support, and financial insecurity are known risk factors for poor maternal mental health (34), the second aim was to document the common causes of poor perinatal mental health to uncover any potential interactions between the identified barriers to service utilization and the causes of poor mental health. Based on this evidence, the third aim was to develop and propose an improved maternal mental health service delivery model in Karnataka's primary care settings.

The two important outputs of this manuscript would be an evidence-based framework that describes the barriers to maternal mental health service utilization in Karnataka, India and its 
116 potential interactions with the common causes of poor perinatal mental health; and the

117 development of an integrated model for universal screening, detection, diagnosis and treatment

118 of mental health conditions in perinatal women that is incorporated within antenatal and

119 postnatal care in primary settings. 


\section{Setting and Participants}

122 In-depth interviews (IDIs) were conducted from August 2019 to April 2020 in Bangalore,

123 Karnataka, to understand the perspectives of a range of local stakeholders relevant to maternal

124 mental health (Table 1). Participants were recruited through a purposive sampling technique to 125 capture the maximum diversity in views. They were four mental health experts (two practicing 126 psychiatrists, one clinical psychologist involved in diagnosing and treating mental health 127 disorders in women during the perinatal period, and one expert in mental health epidemiology).

128 We also interviewed two gynecologists involved in antenatal care in public hospitals of

129 Bengaluru, two officers each from the Directorate of Health and Family Welfare Services,

130 Government of Karnataka (GoK) and Department of Women and Child Development, GoK, one 131 senior state consultant to United Nations Children's Fund (UNICEF), and ten frontline workers 132 (four AWWs, four ASHAs, and two ANMs) from Bengaluru, Karnataka. All frontline workers 133 were females with an average age of 40.7 years (range: $24-57$ years) and at least secondary 134 education levels. Among the eleven specialists, five were females. The minimum qualification of 135 the specialist group was a master's degree.

\section{Ethical Considerations}

137 Ethical approval for this study was granted by the institutional ethics committee of the Indian 138 Institute of Public Health-Hyderabad, Bengaluru campus (IIPH-B). Participants were approached 139 directly or through email with a request for an in-person or telephonic (out-of-station 140 participants) interview, which was expected to be completed within one hour. The objectives of 141 the study were described to the participants at this stage, and voluntary informed consent, which 
142 specifically requested an audio recording of the interview for later transcription, translation, and 143 analysis, was obtained. All interviews were conducted at a time and language convenient to the 144 participant and in a location that maintained the privacy of the conversation. Data from these

145 interviews were strictly used for research purposes only. Confidentiality was ensured by 146 handling audio recordings by key research personnel only, storage in password-protected files, 147 and removing personal identifying information from interview transcripts before sharing data 148 with the larger analysis team.

\section{Data Collection}

150 An initial draft of the semi-structured interview guide was prepared by the research team. Pre151 specified probes were included to encourage discussion of relevant ideas that may be missed in 152 the initial response. Based on the participant's preferences, interviews were conducted either in 153 English or Kannada by a multilingual, trained research staff. The interview began by collecting 154 basic demographic details, followed by open-ended semi-structured questions to elicit elaborated 155 responses. The topic guide included questions related to stakeholders' professional experiences 156 and contact with women during the perinatal period, causes and impact of perinatal depression 157 on mother, child, and the family, and the availability, access, and utilization of mental health 158 services in public health facilities in Karnataka. The bulk of the interview was geared towards 159 discussing stakeholder perceptions on the barriers to the utilization of available and upcoming 160 services related to maternal mental health in the state of Karnataka. Data was collected and 161 analyzed iteratively until saturation was reached. During this process, the interview guide was 162 modified as necessary for subsequent interviews to clarify questions and add probes based on 163 feedback from previous interviews.

\section{Data Analysis}


165 Data analysis followed a thematic approach using the framework analysis method. This involved 166 the following steps:

167 Transcription: Audio-recorded interviews were transcribed in the same language as the 168 interview. Kannada transcripts were further translated into English and referred to for 169 clarifications as needed. Interviews conducted in English were directly transcribed in English.

170 Independent quality checks were done by the research team members to ensure error-free

171 transcription and translation by listening back to random segments of the audio recordings and

172 reading the transcripts simultaneously.

173 Familiarization with the data: Members of the research team thoroughly read and re-read each

174 transcript to familiarize themselves with the whole data set and independently develop an

175 understanding of the initial themes that emerged from participant responses.

176 Developing a working analytical framework: As a first step, the interview guide and familiarity

177 with the data were used to generate an initial list of codes that were mutually agreed upon by the 178 research team. Interviews were coded to extract data on two main themes - what are the barriers 179 to accessing mental health services in Karnataka, and what are the most common causes of poor 180 maternal mental health in the state. Additional notes were taken of evidence demonstrating an 181 interaction between these two broad themes. This initial list was used to code a small set of 182 transcripts and generate new codes where necessary. This exercise was done independently by 183 each member of the analysis team and then discussed in the presence of the whole team to update 184 the initial code list and finalize the definitions for each included code. This formed the initial 185 working analytical framework. NS, MK, and DJ then collectively coded all the remaining 186 transcripts using the initial framework. New emerging themes and codes were noted and 187 discussed during regular team meetings before including them within the framework. Codes 
188 were grouped into themes and sub-themes relevant to the research questions as analysis

189 progressed.

190 Creation of the final framework matrix: NVIVO 12 software (QSR International Pty Ltd) was

191 used to digitally code, compile and chart data within the final framework developed in the

192 previous step. The outcome was a matrix that cross-tabulated the raw data (as quotes) for each

193 code and the participants. This matrix was used to summarize and interpret the data for each

194 theme. Relationships between themes were identified, which informed the interactions between

195 the barriers to accessing perinatal mental health services in Karnataka, the causes of poor

196 maternal mental health, and its impact on the mother, child, and family.

197 This evidence-based framework, along with evidence from the literature on successful maternal

198 mental health service delivery platforms in other countries, was then used to develop and

199 propose an improved model for maternal mental health service delivery for Karnataka. This

200 improved model aimed to address the common perceived barriers summarized in the framework

201 and integrate universal screening of poor maternal mental health in public health facilities by

202 non-specialists to identify women who could benefit from the above services. 


\section{Results}

204 A synthesis of the study's findings is presented as a framework in Fig. 1 and described below.

205 Please refer to Table 2 for illustrative examples of quotes for each category, theme, and

206 subthemes listed in the framework.

207 As demonstrated in Fig. 1, common barriers to perinatal mental health service utilization could 208 be categorized into the following three levels: Health System, Community, and the Family and 209 Individual.

\section{Health-system level barriers}

211 Lack of screening services: There is no mechanism to systematically screen every woman for

212 mental health conditions during the perinatal period, even though this phase marks a period when

213 women proactively make multiple contacts with the health system. Antenatal and postnatal visits

214 are child-centric and largely overlook mental health issues. An unfortunate consequence of the

215 absence of a systematic screening facility is the lack of understanding of the true burden of

216 perinatal mental health problems in the state, as highlighted in Fig.1. Without an accurate

217 estimate of the burden, the design and implementation of effective perinatal mental health

218 service delivery platforms would be hard to achieve.

219 In terms of the format for screening, some stakeholders were of the opinion that mental health

220 screening should involve open-ended conversations by trained providers that indirectly probe the

221 mental health status and associated risk factors during the perinatal period, rather than

222 standardized questionnaires that solely require "ticking boxes."

223 Lack of adequate infrastructure: The quality of the health system is not uniform across the state.

224 Women in rural areas are particularly vulnerable since the availability of even the most basic 
225 maternal and child health services are far from optimal. Mental health services take a backseat

226 when more elementary services are hard to access, although they are likely to add to the stresses

227 associated with pregnancy and childbirth.

228 Lack of sensitization and training of frontline workers: Although frontline workers are poised to

229 identify signs of poor mental health and their associated risk factors since they make multiple

230 contacts with perinatal women over extended periods of time, they typically overlook or avoid

231 conversations around mental health since they are not sensitized or trained to screen, monitor and

232 refer women with mental health conditions to appropriate facilities. This poses a major barrier

233 towards identifying mothers with mental health issues and placing them on a referral pathway

234 when needed. However, counselling support for mental health is starting to be included as a topic

235 during ASHA trainings (see quote 1.1.4 in Table 2). However, it is yet to receive the same level

236 of emphasis as common physical disorders during pregnancy. This lack of training was

237 highlighted by several misconceptions among frontline workers about mental health conditions

238 during pregnancy. For example, many considered anxiety and depression as mental states that

239 could be voluntarily controlled and no need for any counselling or treatment support.

240 Time constraints due to heavy caseloads: Heavy caseloads of health professionals, especially in

241 remote areas, present a major barrier to dedicating adequate time to assess mental health or to

242 counsel women on common causes and risk factors of depression, stress, or anxiety. Frontline

243 workers also expressed their concerns about managing multiple programs that often went beyond

244 women and child health, which left them with limited time to attend to and solve for every

245 woman who came to seek their help. This is particularly important for mental health issues such

246 as depression. The frontline worker may have to proactively reach out to mothers who refuse to

247 engage and spend adequate time building a rapport and trust before treatment and counselling 
248 facilities can be discussed.

249 Community-level barriers

250 Stigma is associated with a mental health disorder: Stigma is one of the most significant and

251 complex barriers that prevent women and their families from seeking support when the mother is

252 mentally unwell, to avoid discussions and gossip amongst community members about the

253 family's mental health issues.

254 Lack of awareness about the need for and potential of treatment: The level of awareness about

255 mental health issues was perceived to be very poor in the general population, which likely

256 contributed to the stigma surrounding the issue. Mental health experts opined that the general

257 public often wrongly assume that mood swings or feeling sad is part of life, even if experienced

258 for extended periods or those which impact daily functioning. Concerns were raised about family

259 perceptions of perinatal depression and anxiety being considered a consequence of physiological

260 changes brought about by pregnancy and, therefore, not needing any follow-up diagnosis or

261 treatment. This poses a major barrier to seeking support, even if services are available.

262 Lack of awareness about service availability and access: Even if mental health issues are

263 identified, and the family is willing to access services, there is a general lack of awareness about

264 local availability of mental health services and how to access them.

265 Lack of social support: As a result of the stigma, the lack of acknowledgment that mental health

266 problems require treatment, and the lack of awareness about available services, there are often

267 low levels of support and encouragement from community members for women to seek mental

268 health treatment actively. In a patriarchal society, women have limited decision-making abilities

269 and typically need the approval of their husbands and elders before seeking medical attention. In 
270 turn, the family's decisions are strongly influenced by community standards, perceptions, and

271 beliefs, making it extremely difficult for a woman to seek treatment when needed.

272 Myths and misconceptions: Participants highlighted that communities often have grave

273 misunderstandings about how common mental health disorders present themselves and when

274 treatment or counselling should be sought. In many cases, women hesitate or fail to seek

275 treatment since they believe their condition is not severe enough to warrant further attention.

276 Myths and misconceptions also arise from false belief systems that the community associates

277 itself with. For example, in rural Karnataka, delivering a baby through C-section is looked down

278 upon and attributed to the mother being 'abnormal.' Others misconceptions include the birthing

279 mother being possessed by ghosts if complications were to arise during the intrapartum period.

280 Additionally, while there is a general acceptance of the notion that maternal mental health

281 impacts the baby, there are no active steps taken by the community to promote mental health,

282 probably due to the misconception that the mother can automatically exert control over her

283 negative emotions for the sake of her baby without any active interventions.

\section{Family and individual level barriers}

285 Family and individual-level factors include the financial burden of availing mental health

286 services, time constraints due to competing interests and commitments, lack of partner and

287 family support, which adversely affects how empowered the woman feels about seeking mental

288 healthcare, as well as her motivation to attend to her own mental and physical health needs.

$289 \quad$ Financial burden related to availing treatment services: Mental health services are perceived to

290 be expensive and expected to impose a heavy financial burden. The perceived burden includes

291 finances for direct payment for services, cost of travel and accommodation in distant urban 
292 locations where services are typically concentrated, and the loss of income arising from being 293 absent from work. Lack of awareness about low-cost services offered by the Manochaitanya 294 program adds to this faulty perception.

295 Lack of support from the partner or family: In a patriarchal society, women's health is often 296 considered to be less important compared to other members in the family. Therefore, they fear a 297 backlash from family members if they seek support for their mental health. This aspect is further 298 exacerbated in women who experience domestic violence since poor interpersonal relationships

299 further reduce the likelihood of being supported to seek treatment. Also, familial conflicts reduce 300 how empowered women may feel to seek out services on their own. In many cases, when 301 perinatal women perceive their families not to support them seeking mental healthcare, they 302 discourage any help they would have otherwise received from supportive frontline workers for 303 fear of abandonment or aggressive family reactions.

304 Lack of time due to multiple competing commitments: During the perinatal period, women face 305 the double burden of household chores and demanding child-care. They often do not have the 306 necessary support at home to take over their duties when they need to dedicate themselves to 307 attending mental health services. This prevents them from utilizing services, even if they are 308 available.

309 Lack of motivation for self-care: The participants perceived women to be less motivated about 310 seeking services for their health. The other family members' needs and conflict avoidance within 311 the family were almost always prioritized over their own.

\section{Risk factors for poor maternal mental health}

313 Participants cited several risk factors that contributed to poor maternal mental health in 
314 Karnataka. Stressors related to domestic violence, husband's alcohol dependence, and financial

315 insecurity were most commonly cited. The woman's lack of empowerment and social support in

316 the household and her community, particularly her inability to make important decisions for

317 herself or her baby, was also highlighted as being common causes for feelings of anxiety and

318 helplessness that many mothers face in day-to-day lives. Poor economic conditions that

319 necessitated mothers to supplement the family's income while simultaneously taking care of an

320 infant or food insecurity that impacted lactation sufficiency were cited as common risk factors

321 for impoverished families. Another important area of concern relates to a preference for a boy

322 child, especially in cases where previous pregnancies led to a girl child being born. This puts

323 undue pressure and is a cause for anxiety during the entire antenatal period. The birth of a girl

324 child often leads to reduced social support within the family, affecting the mother's mental health

325 and reducing her feelings of empowerment within the family.

326 In some cases, poor maternal mental health outcomes result from gross misconduct and ill-

327 treatment of the mother by health professionals while delivering the child, especially in public

328 health facilities. At a time when institutional delivery is encouraged, the experience in some

329 mothers leaves them scarred. Such harsh behavior further exacerbates their vulnerability.

330 Interactions between barriers to service utilization and risk factors of poor maternal

331 mental health

332 Our analysis revealed several factors that pose barriers to utilizing mental health services are also

333 strongly related to the risk factors perceived to contribute to poor maternal mental health. In

334 essence, risk factors of poor mental health increase the barriers to service utilization that operate

335 at the family and the individual level. For example, women who are not empowered to make

336 their own choices about seeking mental healthcare typically also experience domestic violence at 
337 home, particularly from in-laws and alcoholic husbands. Alcoholism in the husband was, in turn,

338 perceived to be related to financial insecurity in the household, which in turn adversely affected

339 the family's decision to seek mental health services, which they perceived as expensive. Women

340 who needed to take on additional work to supplement household income were further

341 disadvantaged since it imposed heavily on their time available to seek services.

342 Women were expected to continue with their regular household activities during the perinatal

343 period, which is more demanding at this time due to pregnancy or child-rearing related

344 exhaustion. This constant exhaustion state further limited the time and motivation required to

345 seek mental health support when required. This was often compounded by unreasonable

346 expectations from family members who did not support their own mental health during their

347 perinatal period. Therefore, they saw no reason why any specialized treatment or counselling

348 would be required in the first place.

349 Perceived impact of poor maternal mental health on the mother, child, and the family

350 Majority of the participants were of the opinion that maternal depression is a public health

351 concern and that it adversely affects the mother, child, and family. Specifically, poor maternal

352 mental health was perceived to adversely impact a mother's self-care practices, mother-child

353 bonding, and her relationship with the rest of the family. It was also broadly acknowledged that

354 these adverse impacts would ultimately lead to poorer child development outcomes.

355 Overall, our framework (Fig. 1) suggests that multiple levels of barriers to service utilization

356 decrease access to available services and impedes our ability to understand the true burden of

357 perinatal mental health conditions in the state. Therefore, all participants unanimously voiced

358 their concerns over the poor state of affairs in dealing with poor maternal mental health in 
359 Karnataka, specifically - limited mental health services available to them, the lack of awareness 360 about those that existed, and the several barriers that women faced in being able to access those 361 services.

362 On the flip side, the framework also suggests that a multi-pronged strategy to address these 363 barriers would improve the uptake of services and have several positive downstream effects. 364 Better utilization of services would reduce the adverse impacts of poor maternal mental health on 365 the mother, child, and family relationships and prioritize integrating perinatal mental health 366 services in primary care settings and increasing demand for more high-quality services. Over 367 time, this would help overcome the dearth of data that impedes the effective implementation, 368 monitoring and evaluation of perinatal mental health programs in the state of Karnataka.

\section{Recommended model for universal identification, referral, and treatment of perinatal} mental health conditions in India

371 Based on this evidence, and drawing from the literature describing successful perinatal mental

372 health programs for low resource settings, we recommend the following model for integrating 373 perinatal mental healthcare in primary care settings in Karnataka (Fig. 2). First, we propose a 374 robust integration of perinatal mental health services with maternal and child health programs, 375 operationalized through screening for common mental health disorders during each antenatal 376 visit, during the postnatal period when the mother brings the child for immunizations, and by 377 ASHA workers during scheduled home visits as part of the Home Based Neonatal Care (HBNC) 378 program (35). Screening could be led by frontline workers such as ASHA's, Anganwadi workers, 379 ANMs, and staff nurses in district and taluk hospitals, Community Health Centers (CHCs), and 380 Primary Health Centers (PHCs). Two different screening approaches could be piloted to test 381 acceptability, feasibility, and efficacy - one questionnaire-based. The other using a structured 
382 interview format - both probed into the levels of stress, anxiety, and depressive symptoms

383 experienced by the mother. As outlined in a World Health Organization (WHO) report on

384 maternal mental health (27), these interactions between frontline workers and mothers should be

385 sensitive, respectful, courteous and non-judgmental, to build a relationship of trust and openness.

386 If the symptoms are mild, the same frontline workers will provide basic counselling and support,

387 which could include active assistance with social and marital problems, connecting women to

388 appropriate agencies that focus on specific areas such as domestic violence or financial aid, and

389 introduce them to peer, support groups, when available. Records would be maintained to ensure

390 follow-up counselling and check-ins during subsequent check-ups. Women with moderate

391 symptoms would be referred to the PHC medical officer for follow-up assessment and referrals

392 as needed. Women who report persistent moderate-to-severe symptoms would be referred

393 directly to the Manochaitanya clinic or the district hospital for evaluation and treatment by a

394 specialist.

395 A novel initiative named the Digital Nerve Center (DiNC) is currently being piloted in two districts

396 of Karnataka. By harnessing technology, it aims to improve access by providing personalized

397 information about available healthcare services and coordinating visits (32). Screening and

398 referrals from the Digital Nerve Centre (DiNC) would also feed into this pipeline following the

399 same logic model (see Fig. 2). Regular refresher training and supervision of all frontline staff

400 would be undertaken to ensure continued delivery of high-quality services and to provide

401 psychological support to staff when needed.

402 Finally, as a preventive and promotive measure, and to improve awareness and reduce stigma,

403 topics on maternal mental health and its common determinants would be discussed in existing

404 platforms related to maternal and child health, integrated with themes known to cause stress 
405 anxiety perinatal period. For example, discussions related to breastfeeding could also include 406 topics on how lactation failure could potentially cause stress, along with a list of action points to 407 follow in such scenarios. Some examples of relevant platforms that could host these discussions 408 include mother's support group meetings led by ASHA's in the pregnancy and postpartum 409 periods, village health and nutrition days (VHNDs), and village health, nutrition, and sanitation 410 committee (VHNC) meetings. 


\section{Discussion}

412 The framework developed in this study (Fig. 1) highlights three key points regarding perinatal

413 mental health service in the state of Karnataka, India, from the perspective of a wide range of

414 local stakeholders who are involved in maternal and child health in various capacities. First, it

415 comprehensively lays out the common barriers to service utilization that operate at multiple

416 levels - the health system, community, family, and the individual. Second, it highlights the inter-

417 relatedness between the above barriers and the risk factors of poor maternal mental health.

418 Finally, the framework posits that addressing these barriers, particularly those related to the

419 family and individual factors, would have several positive downstream effects (highlighted as

420 blue boxes in the framework). It would help counter the risk factors of poor perinatal mental

421 health and its adverse impacts on the mother, child, and family, create awareness about and

422 demand for high-quality mental health services, and enable building a sizeable database to help

423 quantify the true burden of poor maternal mental health in the state. These points are elaborated

424 below.

425 Identification of those who need interventions is the first step to efficient utilization of any health

426 service. Therefore, concerted efforts should be directed towards universal and systematic

427 screening of perinatal women for mental health conditions. A systematic review of screening

428 instruments to assess depression during the perinatal period identified seven commonly used

429 tools in low-resource settings (36). Among them, the Edinburgh Postnatal Depression Scale

430 (EPDS) emerged as the most accurate and sensitive across settings.

431 The institution of a universal screening mechanism needs to go hand-in-hand with training and

432 sensitization of healthcare staff on the use of these instruments. Most health professionals,

433 especially in remote areas, have limited training and time to identify and refer women to 
434 appropriate channels for diagnosis and treatment or provide basic mental health counselling in 435 the absence of available specialist services. These barriers are not unique to India since LMICs, 436 in general, are plagued by inadequate screening and referral mechanisms and shortages of trained

437 health staff, which eventually lead to a huge treatment gap for all mental health conditions, 438 including common perinatal mental health disorders such as depression and anxiety $(37,38)$. The 439 dearth of trained workforce and heavy workload of existing specialist staff may be addressed by 440 combining task-sharing and a stepped-care approach. Several countries that are aiming to 441 integrate mental health in primary care have broadly adopted this strategy with local adaptations 442 (27) such as the National Prenatal Depression Initiative (NPDI) in Australia (39), the Perinatal 443 Mental Health Project in South Africa (37) as well as smaller scale district-level pilot projects in 444 South America, Middle-east and Africa (27). Task-sharing entails training and supporting 445 frontline workers on basic screening and counselling techniques and establishing a clear 446 responsibility and referral pathway for severe and complex cases. This serves the dual purpose of 447 building capacity for mental health treatment at different levels within the health system while 448 freeing up specialist time to focus exclusively on difficult cases $(37,40,41)$.

449 The dedicated perinatal mental health program poised to be launched by the Karnataka 450 government (Mathruchaitanya) will follow a task-sharing, stepped-care approach, thereby 451 promising to address the health system level barriers described above. However, the additional 452 burden of implementing these new mental health programs on already overburdened frontline 453 workers and primary physicians (42) will further impinge on their time and availability. A 454 potential solution may be the continued incentivizing of private partners to provide mental 455 healthcare services in public settings as initiated through the public-private partnership model in 456 the Manochaitanya program (30), or the training of community volunteers who could take on 
457 some of the responsibilities of frontline health workers such as identifying, referring and

458 monitoring individuals with mental health issues in the community. There is a large body of

459 evidence demonstrating the feasibility and efficacy of providing quality mental health services

460 for common mental health disorders by non-specialist community health workers and volunteers.

461 An excellent example is the Thinking Healthy Program and its various local adaptations that

462 were adopted by the WHO as an evidence-based, cost-effective, non-specialist led, community-

463 based intervention for perinatal mental health (43-46).

464 While it is possible to address health system-level barriers through strategic local adaptations of 465 the stepped-care model, the specific barriers that operate at the level of the community, family, 466 and the individual will need more contextual and innovative solutions since biases against mental 467 health disorders are long-standing and deep-seated. Stigma, often arising from significant gaps in 468 knowledge about mental health conditions in the community and extant misconceptions 469 regarding how they present, emerged as an important community-level barrier for women to 470 access services. Stigma also resulted in community and family members failing to provide the 471 necessary social support desperately needed by perinatal women to seek services. Recent 472 systematic reviews list stigma as an important barrier to accessing services even in developed 473 nations like the UK (26,47), and a meta-analytic review of 56 articles (48) reported a moderate 474 negative association (-0.27) between stigma and help-seeking behavior, highlighting it as one of 475 the key deterrents to service utilization that needs addressing across the board.

476 One way to counter barriers related to stigma is by increasing awareness about mental health 477 conditions in the community, the potential for their cost-effective treatment, training community 478 leaders on communication strategies that build sympathetic narratives about mental health 479 conditions, and avoiding misconceptions about their presentation (49). Additionally, increased 
awareness about the risk factors for poor maternal mental health such as domestic violence and

481 stressors related to voicing a preference for a boy child may further help the family to avoid

482 stressful behaviors that are known to impact the mother's mental health adversely, thereby acting

483 as a preventive measure. The Indian government's schemes that support the girl child such as the

484 "Beti bachao, beti padhao" (Save the girl child, educate the girl child) and "Sukanya Samriddhi

485 Yojana” (Girl child prosperity scheme) will further bolster such efforts.

486 Several experts thought that increased visibility of the Manochaitanya program, as is evident

487 from the dramatic increase in its uptake in the past six years (31), would greatly help generate the 488 necessary awareness about mental health disorders in the community. Continued sensitization 489 and capacity building of frontline workers on mental health disorders would build credibility for 490 the program within the community as they get exposed to more knowledge about different 491 mental health conditions and their determinants on the one hand, and the support they receive for 492 affordable and accessible specialist healthcare on the other. Finally, the provision of universal 493 screening for maternal mental health with well-planned and efficient care pathways may go a 494 long way to counter stigma-related barriers to accessing services. Together, these may lead to 495 shifts in community perspectives about mental health and increase mental health-seeking 496 behaviours. These measures will also help address some of the family and individual level 497 barriers, including misconceptions regarding mental health treatment being prohibitively 498 expensive and time-intensive, and empower women to voice their need for mental health 499 treatment in a more accepting society.

500 An interesting outcome of our analysis was the interaction between factors that were perceived 501 as barriers to service utilization and the causes of poor maternal mental health. Based on this 502 observed interaction, we propose that solving for these common underlying factors may reap the 
503 dual benefit of improving service utilization and reduce the risk of poor mental health. There is

504 evidence to show that improving mental health literacy at the community and family levels

505 improves mental health outcomes, partly by promoting help-seeking behavior (50). Specifically,

506 in the Karnataka context, women are expected to continue with usual household duties through

507 the perinatal period with little support from the family. They may also experience domestic

508 violence and have poor decision-making abilities in the family. This lack of social support and

509 increased stress are both risk factors for poor mental health and barriers to seeking treatment.

510 Therefore, solving for these common underlying factors through increased awareness about the

511 negative consequences of maternal stress on child health and development may simultaneously

512 spur improved attitudes towards providing social support to seek mental healthcare when needed,

513 as well as provide increased support to help reduce maternal stress in the immediate postpartum

514 period. Similarly, interventions to address physical, verbal, or emotional abuse, lack of partner or

515 family support, and financial insecurity may have spin-off effects on both fronts.

516 Based on our findings and available evidence in the literature, we have proposed a model that

517 combines task-sharing and a stepped-care approach for perinatal mental health in Karnataka,

518 which can unify the several mental health programs that have been recently been launched or are

519 in the pipeline. We believe that this unified model holds promise since similar models have

520 successfully been implemented at varying levels of scale in other low-resource settings such as

521 South Africa, Uganda, and Kerala, India (29,37,38,51,52). An important component is

522 integrating perinatal mental health delivery in existing maternal and child health programs and

523 largely led by trained non-specialist frontline workers. Successful implementation of this model

524 may lead to increased uptake of mental health services, thereby providing the necessary demand-

525 driven impetus to strengthen the Indian mental health infrastructure further, ensure increased 
526 accessibility, a broader range of available services, and the appointment of dedicated care

527 providers for the provision of mental health services in the future.

\section{$528 \quad$ Limitations of the study}

529 First, certain barriers to mental health service utilization may have been overlooked, especially

530 those specific to the most remote areas in Karnataka, since this manuscript documents the

531 perceptions and opinions of participants largely based in urban areas. Second, data was only

532 collected through in-depth interviews, which does not allow for the emergence of group

533 consensus on topics of interest as is possible through focused-group discussions. Finally, a major

534 limitation of the proposed model is the addition of yet another program to an already

535 overburdened health system. However, the proposed solutions and the socio-economic benefits it

536 will potentially accrue, would likely encourage the system to sustain and further strengthen

537 mental healthcare delivery in primary care settings.

\section{Conclusion}

539 We identified multiple barriers to the effective utilization of mental health services in Karnataka,

540 ranging across the health system, community, family, and individual levels. Based on our results

541 and drawing examples from the literature, we have proposed a stepped-care model that integrates

542 all the existing relevant programs in Karnataka into a universal perinatal mental health program

543 to realize the goal of making mental health services available and accessible to all women during

544 this critical period of their lives. In turn, this may reduce the risk of adverse neonatal, infant, and

545 child health and development outcomes and have additional spillover benefits of increased

546 awareness about mental health conditions in the community, reduced stigma, and eventually lead

547 to improved healthcare-seeking behavior in the community. Needless to say, although 
548 contextualized for Karnataka, India, similar models would also be applicable to the rest of the

549 country and other low-resource settings across the globe. However, important limitations related

550 to heavy caseloads in remote locations with limited specialist support must be seriously

551 considered during the iterative refinement of these programs in the future since time constraints

552 of the existing overburdened healthcare staff would overturn any attempts to implement any of

553 these programs effectively. Therefore, relevant stakeholders must continue to track

554 implementation challenges across different contexts and keep innovating to address common

555 barriers to help transform these ambitious but fledgling programs into effective well-oiled

556 machinery. Once empirically tested and refined, components of the optimized mental health

557 service delivery model can inform policy formulation in India and other LMICs. 


\section{$558 \quad$ List of abbreviations}

559 LMICs (Low and middle-income countries); ASHAs (Accredited Social Health Activists);

560 AWW (Anganwadi Workers); ANM (Auxillary Nurse Midwife); PPP (Public-private

561 partnership); RMNCH (Reproductive, maternal and child health)

\section{Declarations}

\section{Ethics approval and consent to participate}

564 All procedures contributing to this work comply with the ethical standards of the relevant

565 national and institutional committees on human experimentation and with the Helsinki

566 declaration of 1975, as revised in 2008. Ethical approval for the study was obtained from the

567 Indian Institute of Public Health-Bengaluru campus Ethics Committee (Approval No: IIPHHB/

568 TRCIEC/146/2019). Informed consent was obtained from all participants prior to data collection.

\section{Consent for publication}

570 Not applicable

571 Availability of data and materials

572 The datasets used and analyzed in the current study are available from the corresponding author

573 on reasonable request.

\section{Competing interests}

575 The authors declare they have no competing interests.

\section{$576 \quad$ Funding}

577 This study was supported by an INSPIRE Faculty Award granted to DM (award number 
578 DST/INSPIRE/04-I/2016/000001) and an Intermediate Fellowship by the DBT-Wellcome Trust

579 India Alliance (Clinical and Public Health research fellowship) to GRB (grant number:

580 IA/CPHI/14/1/501499). The content is solely the responsibility of the authors. The funding

581 bodies were not involved in the design of the study, the collection, analysis, and interpretation of

582 data, and in writing of the manuscript.

583 Author's contributions

584 DM and GRB conceptualised and designed the study. DM, SAG, ND, MK, and DAJ carried out 585 data collection, analysis and interpretation. DM, ND, DAJ wrote the first draft of the manuscript. 586 All authors reviewed the first and subsequent drafts of the manuscript and approved the final 587 version to be published.

588 Acknowledgements

589 Not applicable 


\section{References}

591 1. Bhutta ZA, Lassi ZS, Blanc A, Donnay F. Linkages Among Reproductive Health, Maternal Health, and Perinatal Outcomes. Vol. 34, Seminars in Perinatology. 2010. p. 434-45.

2. Nikolaeva E, Merenkova V. The Interrelation of the Mother's Health Status with the State of Health of First- and Second-Year-Old Children. In: Maternal and Child Health Matters Around the World. 2020.

3. Rutherford C, Sharp H, Hill J, Pickles A, Taylor-Robinson D. How does perinatal maternal mental 597 health explain early social inequalities in child behavioural and emotional problems? Findings from the Wirral Child Health and Development Study. PLoS One. 2019;14(5).

4. Bennett IM, Schott W, Krutikova S, Behrman JR. Maternal mental health, and child growth and development, in four low-income and middle-income countries. J Epidemiol Community Health [Internet]. 2016 Feb;70(2):168-73. Available from: https://jech.bmj.com/lookup/doi/10.1136/jech2014-205311

5. Srinivasan K, Satyanarayana V, Lukose A. Maternal mental health in pregnancy and child behavior. Indian J Psychiatry [Internet]. 2011;53(4):351. Available from: http://www.indianjpsychiatry.org/text.asp?2011/53/4/351/91911

606

6. Tiffany Burkhardt. Predicting Emotion Regulation in Early Childhood: The Impact of Maternal Well-Being, Infant Crying, and Dyadic Mutuality Maternal Well-Being, Infant Crying, and Dyadic Mutuality. Loyola University Chicago; 2014.

609 7. Venkatesh S, Vindhya J, Nath A. Maternal mental health and its influence on infant growth and development: A systematic review of observational studies in South and East Asia. Vol. 12, Indian Journal of Health Sciences and Biomedical Research (KLEU). 2019. p. 103.

612 8. Tough SC, Siever JE, Leew S, Johnston DW, Benzies K, Clark D. Maternal mental health predicts 
risk of developmental problems at 3 years of age: follow up of a community based trial. BMC Pregnancy Childbirth [Internet]. 2008 Dec 6;8(1):16. Available from: http://bmcpregnancychildbirth.biomedcentral.com/articles/10.1186/1471-2393-8-16

9. Gete S, Calderon-Margalit R, Grotto I, Ornoy A. A comparison of the effects of maternal anxiety and depression on child development. Eur J Public Health [Internet]. 2019 Nov 1;29(Supplement_4). Available from: https://academic.oup.com/eurpub/article/doi/10.1093/eurpub/ckz185.275/5624395

10. Woody CA, Ferrari AJ, Siskind DJ, Whiteford HA, Harris MG. A systematic review and metaregression of the prevalence and incidence of perinatal depression. Vol. 219, Journal of Affective Disorders. 2017. p. 86-92.

11. Pai K, Shruti S, Hulegar A, Sandeep K. Prevalence of antenatal depression and gender preference: A cross sectional study among Mangalore population, Karnataka, India. J Pharm Biomed Sci [Internet]. 2013;29:1011-4. Available from: http://eprints.manipal.edu/id/eprint/137077

12. Sheeba B, Nath A, Metgud CS, Krishna M, Venkatesh S, Vindhya J, et al. Prenatal Depression and Its Associated Risk Factors Among Pregnant Women in Bangalore: A Hospital Based Prevalence Study. Front Public Heal [Internet]. 2019 May 3;7. Available from: https://www.frontiersin.org/article/10.3389/fpubh.2019.00108/full

13. United Nations. Transforming our world: the 2030 agenda for sustainable development. [Internet]. 2015. Available from: https://sustainabledevelopment.un.org/post2015/transformingourworld

14. Saraceno B, van Ommeren M, Batniji R, Cohen A, Gureje O, Mahoney J, et al. Barriers to improvement of mental health services in low-income and middle-income countries. Vol. 370, Lancet. 2007. p. 1164-74.

15. Bayrampour H, Hapsari AP, Pavlovic J. Barriers to addressing perinatal mental health issues in 
midwifery settings. Vol. 59, Midwifery. Churchill Livingstone; 2018. p. 47-58.

637 16. Viveiros CJ, Darling EK. Barriers and facilitators of accessing perinatal mental health services:

638 The perspectives of women receiving continuity of care midwifery. Midwifery [Internet]. 2018 [cited 2020 Nov 18];65:8-15. Available from: www.elsevier.com/locate/midw

17. Ford E, Roomi H, Hugh H, Van Marwijk H. Understanding barriers to women seeking and receiving help for perinatal mental health problems in UK general practice: Development of a questionnaire. Prim Heal Care Res Dev [Internet]. 2019 [cited 2020 Nov 18];20(e156):1-8. Available from: /pmc/articles/PMC7003527/?report=abstract

18. Eaton J, McCay L, Semrau M, Chatterjee S, Baingana F, Araya R, et al. Scale up of services for 645 mental health in low-income and middle-income countries [Internet]. Vol. 378, The Lancet. 2011. p. 1592-603. Available from: https://linkinghub.elsevier.com/retrieve/pii/S014067361160891X

647 19. Wang PS, Aguilar-Gaxiola S, Alonso J, Angermeyer MC, Borges G, Bromet EJ, et al. Use of 648 mental health services for anxiety, mood, and substance disorders in 17 countries in the WHO world mental health surveys. Lancet [Internet]. 2007 Sep;370(9590):841-50. Available from: https://linkinghub.elsevier.com/retrieve/pii/S0140673607614147

651 20. Sagar R, Pattanayak RD, Chandrasekaran R, Chaudhury PK, Deswal BS, Lenin Singh RK, et al. 652 Twelve-month prevalence and treatment gap for common mental disorders: Findings from a large653 scale epidemiological survey in India. Indian J Psychiatry [Internet]. 59(1):46-55. Available from: 654 http://www.ncbi.nlm.nih.gov/pubmed/28529360

655 21. Kopelman RC, Moel J, Mertens C, Stuart S, Arndt S, O’Hara MW. Barriers to Care for Antenatal 656 Depression. Psychiatr Serv [Internet]. 2008 Apr 1 [cited 2020 Nov 18];59(4):429-32. Available from: /pmc/articles/PMC3652590/?report=abstract

658 22. Singh OP. Closing treatment gap of mental disorders in India: Opportunity in new competency- 
based Medical Council of India curriculum. Indian J Psychiatry [Internet]. 2018;60(4):375-6. Available from: http://www.ncbi.nlm.nih.gov/pubmed/30581200

661

662

663

664

665

666

667

23. Knaak S, Mantler E, Szeto A. Mental illness-related stigma in healthcare: Barriers to access and care and evidence-based solutions. Healthc Manag forum [Internet]. 2017 Mar;30(2):111-6. Available from: http://www.ncbi.nlm.nih.gov/pubmed/28929889

24. Chisholm D, Docrat S, Abdulmalik J, Alem A, Gureje O, Gurung D, et al. Mental health financing challenges, opportunities and strategies in low- and middle-income countries: findings from the Emerald project. BJPsych open [Internet]. 2019 Aug 6;5(5):e68. Available from: http://www.ncbi.nlm.nih.gov/pubmed/31530327

25. Saxena S, Sharan P. Financing of mental health services: an international perspective. Int Psychiatry [Internet]. 2004 Oct 2;1(6):3-4. Available from: https://www.cambridge.org/core/product/identifier/S1749367600006925/type/journal_article

26. Sambrook Smith M, Lawrence V, Sadler E, Easter A. Barriers to accessing mental health services for women with perinatal mental illness: systematic review and meta-synthesis of qualitative studies in the UK. BMJ Open [Internet]. 2019;9(1):e024803. Available from: http://www.ncbi.nlm.nih.gov/pubmed/30679296

27. Funk M, Ivbijaro G. Integrating mental health into primary care : a global perspective. 2008.

28. Unützer J, Carlo AD, Collins PY. Leveraging collaborative care to improve access to mental health care on a global scale [Internet]. Vol. 19, World Psychiatry. 2020. p. 36-7. Available from: https://onlinelibrary.wiley.com/doi/abs/10.1002/wps.20696

29. Ganjekar S, Thekkethayyil AV, Chandra PS. Perinatal mental health around the world: priorities for research and service development in India. BJPsych Int [Internet]. 2020 Feb 27;17(1):2-5. Available from: 
683 30. Manjunatha N. Karnataka Mental Health (Manochaitanya) Programme: Indian Psychiatric Society $684-$ Karnataka Chapter (IPS-KC) in 'Public Private Partnership' (PPP) model. Indian Psychiatr Soc $685 \quad$ Karnataka Chapter Newsl. 2016;13.

686 31. Agarwal P, Manjunatha N, Parthasarathy R, Kumar C, Kelkar R, Math S, et al. A performance 687 audit of first 30 months of manochaitanya programme at secondary care level of Karnataka, India. 688 Indian J Community Med. 2019;44(3):222-4.

32. Making Healthcare Efficient [Internet]. Available from: https://www.tata.com/newsroom/makinghealthcare-efficient-digital-nerve-centre-dinc

33. LAQSHYA: Labour Room Quality Improvement Initiative [Internet]. Available from: http://nhsrcindia.org/sites/default/files/LaQshya- Labour Room Quality Improvement Initiative Guideline.pdf

694 34. Biaggi A, Conroy S, Pawlby S, Pariante CM. Identifying the women at risk of antenatal anxiety 695 and depression: A systematic review. J Affect Disord [Internet]. 2016 Feb;191:62-77. Available from: http://www.ncbi.nlm.nih.gov/pubmed/26650969

697 35. Neogi SB, Sharma J, Chauhan M, Khanna R, Chokshi M, Srivastava R, et al. Care of newborn in 698 the community and at home. J Perinatol [Internet]. 2016;36(s3):S13-7. Available from: http://www.ncbi.nlm.nih.gov/pubmed/27924109

36. Chorwe-Sungani G, Chipps J. A systematic review of screening instruments for depression for use in antenatal services in low resource settings. BMC Psychiatry [Internet]. 2017;17(1):112. Available from: http://www.ncbi.nlm.nih.gov/pubmed/28340609

37. Honikman S, van Heyningen T, Field S, Baron E, Tomlinson M. Stepped care for maternal mental 704 health: a case study of the perinatal mental health project in South Africa. PLoS Med [Internet]. 
38. Baron EC, Hanlon C, Mall S, Honikman S, Breuer E, Kathree T, et al. Maternal mental health in primary care in five low- and middle-income countries: a situational analysis. BMC Health Serv Res [Internet]. 2016 Feb 16;16:53. Available from: http://www.ncbi.nlm.nih.gov/pubmed/26880075

39. Yelland JS, Sutherland GA, Wiebe JL, Brown SJ. A national approach to perinatal mental health in Australia: exercising caution in the roll-out of a public health initiative. Med J Aust [Internet]. 2009 Sep 7;191(5):276-9. Available from: http://www.ncbi.nlm.nih.gov/pubmed/19740052

40. Rojas G, Fritsch R, Solis J, Jadresic E, Castillo C, González M, et al. Treatment of postnatal depression in low-income mothers in primary-care clinics in Santiago, Chile: a randomised controlled trial. Lancet (London, England) [Internet]. 2007 Nov 10;370(9599):1629-37. Available from: http://www.ncbi.nlm.nih.gov/pubmed/17993363

41. Sikander S, Ahmad I, Atif N, Zaidi A, Vanobberghen F, Weiss HA, et al. Delivering the Thinking Healthy Programme for perinatal depression through volunteer peers: a cluster randomised controlled trial in Pakistan. The Lancet Psychiatry [Internet]. 2019 Feb;6(2):128-39. Available from: https://linkinghub.elsevier.com/retrieve/pii/S221503661830467X

42. Sharma R, Webster P, Bhattacharyya S. Factors affecting the performance of community health workers in India: a multi-stakeholder perspective. Glob Health Action [Internet]. 2014 Dec 13;7(1):25352. Available from: https://www.tandfonline.com/doi/full/10.3402/gha.v7.25352

43. Fisher J, Nguyen H, Mannava P, Tran H, Dam T, Tran H, et al. Translation, cultural adaptation and field-testing of the Thinking Healthy Program for Vietnam. Global Health [Internet]. 2014 May 15;10:37. Available from: http://www.ncbi.nlm.nih.gov/pubmed/24886165

44. Zafar S, Sikander S, Hamdani SU, Atif N, Akhtar P, Nazir H, et al. The effectiveness of 
Technology-assisted Cascade Training and Supervision of community health workers in delivering the Thinking Healthy Program for perinatal depression in a post-conflict area of Pakistan - study protocol for a randomized controlled tria. Trials [Internet]. 2016 Apr 6;17:188. Available from: http://www.ncbi.nlm.nih.gov/pubmed/27048477

45. Sikander S, Lazarus A, Bangash O, Fuhr DC, Weobong B, Krishna RN, et al. The effectiveness and cost-effectiveness of the peer-delivered Thinking Healthy Programme for perinatal depression in Pakistan and India: the SHARE study protocol for randomised controlled trials. Trials [Internet]. 2015 Nov 25;16:534. Available from: http://www.ncbi.nlm.nih.gov/pubmed/26604001

46. Fuhr DC, Weobong B, Lazarus A, Vanobberghen F, Weiss HA, Singla DR, et al. Delivering the Thinking Healthy Programme for perinatal depression through peers: an individually randomised controlled trial in India. The lancet Psychiatry [Internet]. 2019;6(2):115-27. Available from: http://www.ncbi.nlm.nih.gov/pubmed/30686385

47. Watson H, Harrop D, Walton E, Young A, Soltani H. A systematic review of ethnic minority women's experiences of perinatal mental health conditions and services in Europe. PLoS One [Internet]. 2019;14(1):e0210587. Available from: http://www.ncbi.nlm.nih.gov/pubmed/30695019

48. Clement S, Schauman O, Graham T, Maggioni F, Evans-Lacko S, Bezborodovs N, et al. What is the impact of mental health-related stigma on help-seeking? A systematic review of quantitative and qualitative studies. Psychol Med [Internet]. 2015 Jan 21;45(1):11-27. Available from: https://www.cambridge.org/core/product/identifier/S0033291714000129/type/journal_article

49. McGinty E, Pescosolido B, Kennedy-Hendricks A, Barry CL. Communication Strategies to Counter Stigma and Improve Mental Illness and Substance Use Disorder Policy. Psychiatr Serv [Internet]. 2018 Feb;69(2):136-46. Available from: https://psychiatryonline.org/doi/10.1176/appi.ps.201700076 
intervention for mental disorders. Med J Aust [Internet]. 2007 Oct;187(S7). Available from:

754 51. van Heyningen T, Myer L, Tomlinson M, Field S, Honikman S. The development of an ultra755 short, maternal mental health screening tool in South Africa. Glob Ment Heal (Cambridge, 756 England) [Internet]. 2019;6:e24. Available from: http://www.ncbi.nlm.nih.gov/pubmed/31662879

757 52. Kigozi F, Ssebunnya J, Kizza D, Cooper S, Ndyanabangi S, Mental Health and Poverty Project. 758 An overview of Uganda's mental health care system: results from an assessment using the world 759 health organization's assessment instrument for mental health systems (WHO-AIMS). Int J Ment Health Syst [Internet]. 2010 Jan 20;4(1):1. Available from: http://www.ncbi.nlm.nih.gov/pubmed/20180979 


\section{Figures and Tables}

764 Table 1: Types and number of health service providers interviewed for this study

\begin{tabular}{|c|c|c|c|}
\hline S No & Level of expertise & Profession & $\mathbf{N}$ \\
\hline 1 & \multirow{3}{*}{$\begin{array}{l}\text { Mental health } \\
\text { specialists }\end{array}$} & Psychiatrists & 2 \\
\hline 2 & & Clinical Psychologist & 1 \\
\hline 4 & & Mental health epidemiologist & 1 \\
\hline 6 & $\begin{array}{l}\text { Women's health } \\
\text { specialist }\end{array}$ & Gynecologist & 2 \\
\hline 5 & \multirow{3}{*}{$\begin{array}{l}\text { Health systems policy, } \\
\text { administration and } \\
\text { implementation }\end{array}$} & Directorate of Health and Family Welfare $(\mathrm{RCH})^{\#}$, Govt of Karnataka & 2 \\
\hline 8 & & Department of Women and Child Development, Govt of Karnataka & 1 \\
\hline 7 & & UNICEF State Consultant & 2 \\
\hline 9 & \multirow{3}{*}{$\begin{array}{l}\text { Non-specialist health } \\
\text { providers / frontline } \\
\text { workers }\end{array}$} & Auxiliary Nurse-Midwife (ANM) & 2 \\
\hline 10 & & Anganwadi Worker (AWW) & 4 \\
\hline 11 & & Accredited Social Health Activist (ASHA) worker & 4 \\
\hline & Total & & 21 \\
\hline
\end{tabular}




\begin{tabular}{|c|c|c|c|c|}
\hline $\begin{array}{l}\text { Sr } \\
\text { No. }\end{array}$ & Category & Theme & Sub-theme & Illustrative quote \\
\hline \multirow[t]{6}{*}{1} & \multirow[t]{6}{*}{$\begin{array}{l}\text { Barriers to } \\
\text { service } \\
\text { utilization }\end{array}$} & \multirow{6}{*}{$\begin{array}{l}1.1 \\
\text { Health- } \\
\text { System } \\
\text { level } \\
\text { barriers }\end{array}$} & $\begin{array}{l}1.1 .1 \\
\text { Lack of screening } \\
\text { services }\end{array}$ & $\begin{array}{l}\text { "There is no early detection of mental health problems. The main problem with mental } \\
\text { health is its detection and the skills required for its detection. These skills should } \\
\text { improve." }\end{array}$ \\
\hline & & & $\begin{array}{l}1.1 .2 \\
\text { Format of } \\
\text { screening } \\
\text { questionnaire }\end{array}$ & $\begin{array}{l}\text { "Someone needs to ask the mother, "are you feeling okay" instead of asking a } \\
\text { structured questionnaire. If we ask, she may feel comfortable and may say things that } \\
\text { are happening to her. She may tell the reasons also. Later, we can arrange for follow- } \\
\text { up check-ups and treatments." }\end{array}$ \\
\hline & & & $\begin{array}{l}1.1 .3 \\
\text { Lack of adequate } \\
\text { infrastructure }\end{array}$ & $\begin{array}{l}\text { "Many times, the doctors are not available at the PHCs (primary health centers). } \\
\text { There are facilities, but what about accessibility? We see women deliver at home } \\
\text { because of the non-availability of ambulance services on time. When the condition is } \\
\text { so, how can we expect support for mental health?" }\end{array}$ \\
\hline & & & $\begin{array}{l}1.1 .4 \\
\text { Lack of adequate } \\
\text { training of } \\
\text { frontline workers }\end{array}$ & $\begin{array}{l}\text { "We have the satellite-based training for ASHA workers ... around four thousand } \\
\text { ASHA workers are trained every day. We add these mental health training modules in } \\
\text { that. It may not occupy the same time and place as preventing hypertensive disorders } \\
\text { or the correction of anaemia. However, we have initiated this to introduce the concept } \\
\text { of mental disorders during pregnancy and the necessity to address" }\end{array}$ \\
\hline & & & & $\begin{array}{l}\text { "Some people get very tensed and upset; They should remain calm." <misconceptions } \\
\text { among frontline workers due to lack of training> }\end{array}$ \\
\hline & & & $\begin{array}{l}1.1 .5 \\
\text { Time constraints } \\
\text { due to heavy } \\
\text { caseloads }\end{array}$ & $\begin{array}{l}\text { "The biggest challenge is that the gynaecologist has a huge number to cover. If he/she } \\
\text { asks one question, how are you? the <perinatal> woman will keep talking. My } \\
\text { husband is a problem, I have financial problems, my child has this, then I am worried } \\
\text { whether I will have a baby boy or not. Here time is the constraint. I think that is the } \\
\text { biggest barrier. Otherwise, every gynaecologist, every paediatrician, every mental }\end{array}$ \\
\hline
\end{tabular}




\begin{tabular}{|c|c|c|c|c|}
\hline $\mathbf{S r}$ & Category & Theme & Sub-theme & Illustrative quote \\
\hline & & \multirow[t]{4}{*}{\begin{tabular}{|l|}
1.2 \\
Community \\
level \\
barriers
\end{tabular}} & $\begin{array}{l}1.2 .1 \\
\text { Stigma associated } \\
\text { with diagnosis of } \\
\text { a mental health } \\
\text { condition }\end{array}$ & $\begin{array}{l}\text { "They feel awkward about everyone starting to discuss the issue, so they behave like all } \\
\text { is good in their life when they are in a group. They do not come forward due to the fear } \\
\text { of society. People fear society." } \\
\text { "Whenever a female child is born the mother receives a sympathetic look. A woman is } \\
\text { never given the place she deserves when she achieves something; we aren't ready to } \\
\text { accept it." }\end{array}$ \\
\hline & & & $\begin{array}{l}1.2 .2 \\
\text { Lack of } \\
\text { awareness about } \\
\text { the need for and } \\
\text { potential of } \\
\text { treatment }\end{array}$ & $\begin{array}{l}\text { "We don't speak about mental health. That is the main barrier." } \\
\text { "Women ignore the problem and continue to stay in the misconception that some things } \\
\text { are common in such situations." } \\
\text { "We refer women to the psychiatrist, but they will not be ready to go anywhere. We tell } \\
\text { her to go to the office meant for domestic violence, but she refuses to go and says this } \\
\text { is the story of every household, and she always hesitates to move forward." }\end{array}$ \\
\hline & & & $\begin{array}{l}1.2 .3 \\
\text { Lack of } \\
\text { awareness about } \\
\text { service } \\
\text { availability }\end{array}$ & $\begin{array}{l}\text { "We are blessed in Karnataka to have psychiatrists and psychologists in all districts in } \\
\text { Karnataka, along with teams in district hospitals and medical colleges." } \\
\text { "We have counselling facilities, the government has provided many, but we don't know } \\
\text { how much people have understood it." }\end{array}$ \\
\hline & & & $\begin{array}{l}1.2 .4 \\
\text { Lack of social } \\
\text { support }\end{array}$ & $\begin{array}{l}\text { "Just after six or seven months, they have to go to work and take care of kids. These } \\
\text { are some physical challenges. Those below the poverty line and people who work at the } \\
\text { grass root level face more of these issues as they have to handle many things at the }\end{array}$ \\
\hline
\end{tabular}




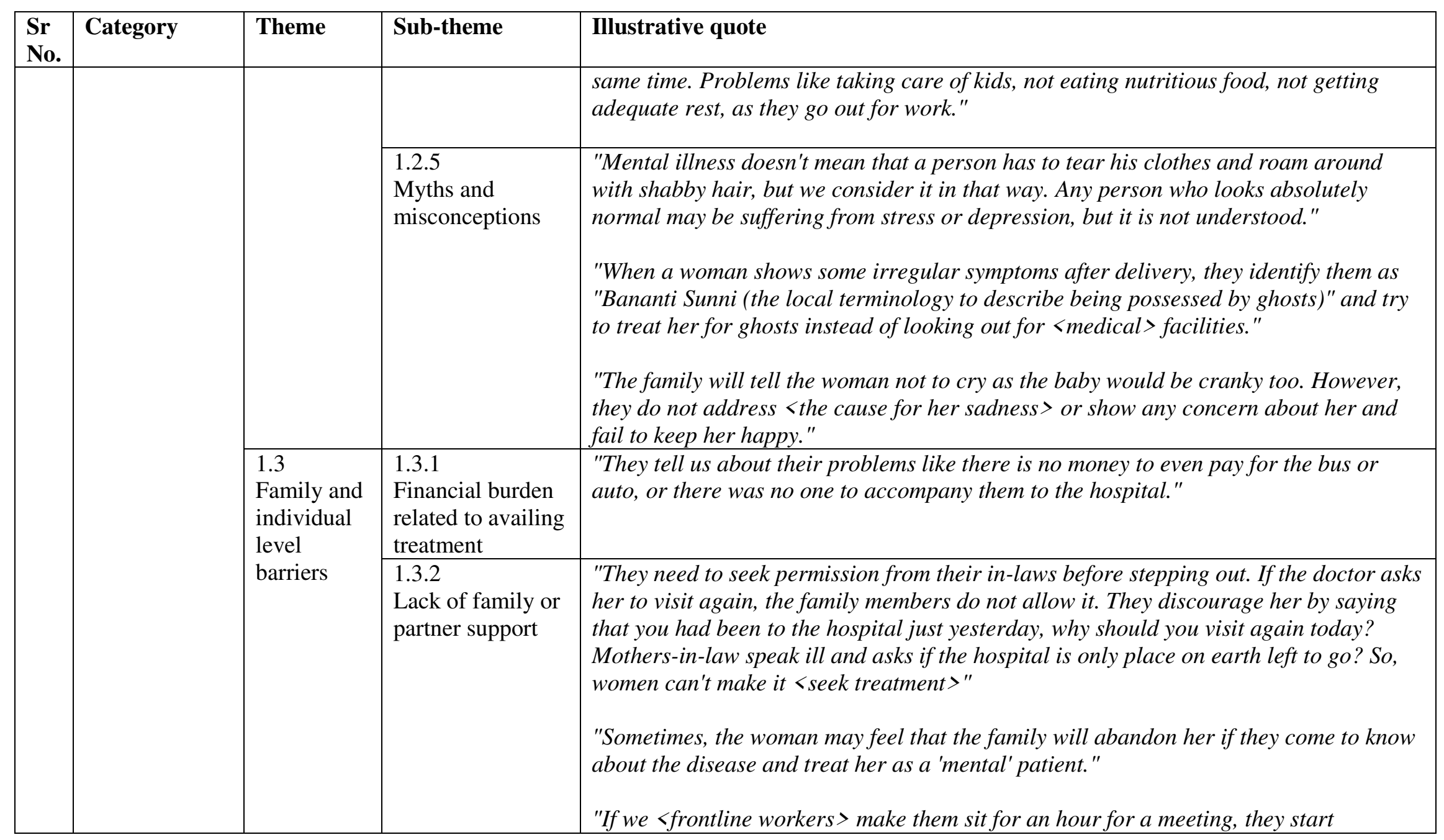




\begin{tabular}{|c|c|c|c|c|}
\hline Sr & Category & Theme & Sub-theme & Illustrative quote \\
\hline \multirow[t]{2}{*}{2} & \multirow[t]{2}{*}{$\begin{array}{l}\text { Risk factors of } \\
\text { poor maternal } \\
\text { mental health }\end{array}$} & \multicolumn{2}{|c|}{$\begin{array}{l}\text { - Preference for a boy child } \\
\text { - Lack of empowerment }\end{array}$} & $\begin{array}{l}\text { "Some people say they have a feeling of fear before delivery. When probed, they talk } \\
\text { about the pressure from the family regarding having a baby boy and that she will not } \\
\text { be allowed to go back home if she happens to deliver a girl. They even complain about } \\
\text { the family not taking proper care, not allowing them to go outdoors, not even to their } \\
\text { parental house." }\end{array}$ \\
\hline & & \multicolumn{2}{|c|}{$\begin{array}{l}\text { - Domestic violence } \\
\text { - Lack of partner and family } \\
\text { support } \\
\text { - Financial hardships }\end{array}$} & $\begin{array}{l}\text { "Some husbands drink and don't bother at all about their wives. They never bring them } \\
\text { to the hospital at any point of time. Never bring a single thing home. Mothers-in-law } \\
\text { complain that she doesn't work and only breastfeeds. These women don't have enough } \\
\text { food to eat and continuously worry that this will lead to low milk production. She has } \\
\text { to spend sleepless nights, and on top of that they blame for her for the girl child." }\end{array}$ \\
\hline
\end{tabular}




\begin{tabular}{|c|c|c|c|c|}
\hline $\mathbf{S r}$ & Category & Theme & Sub-theme & Illustrative quote \\
\hline & & \multicolumn{2}{|c|}{$\begin{array}{l}\text { Ill-treatment by health } \\
\text { professionals during the intra- } \\
\text { partum period }\end{array}$} & $\begin{array}{l}\text { "Women have faced difficulty during delivery, sometimes they are tortured by staff in } \\
\text { the government hospitals and they end up saying they don't want a child due to the ill- } \\
\text { treatment. Girls who are } 18 \text { years of age suffer a lot during delivery and feel that this } \\
\text { was unnecessary at this point in time. }\end{array}$ \\
\hline 3 & $\begin{array}{l}\text { Impact of } \\
\text { poor maternal } \\
\text { mental health }\end{array}$ & \multicolumn{2}{|c|}{$\begin{array}{l}\text { Impact on } \\
\text { - child } \\
\text { - mother-baby bonding } \\
\text { - family relationships }\end{array}$} & $\begin{array}{l}\text { "They are disinterested in eating, doing their work, and all other things. They don't } \\
\text { even bother to eat, bathe, or keep themselves healthy. They do not even think about the } \\
\text { newborn, and no bonding is built between the child and the mother." }\end{array}$ \\
\hline
\end{tabular}




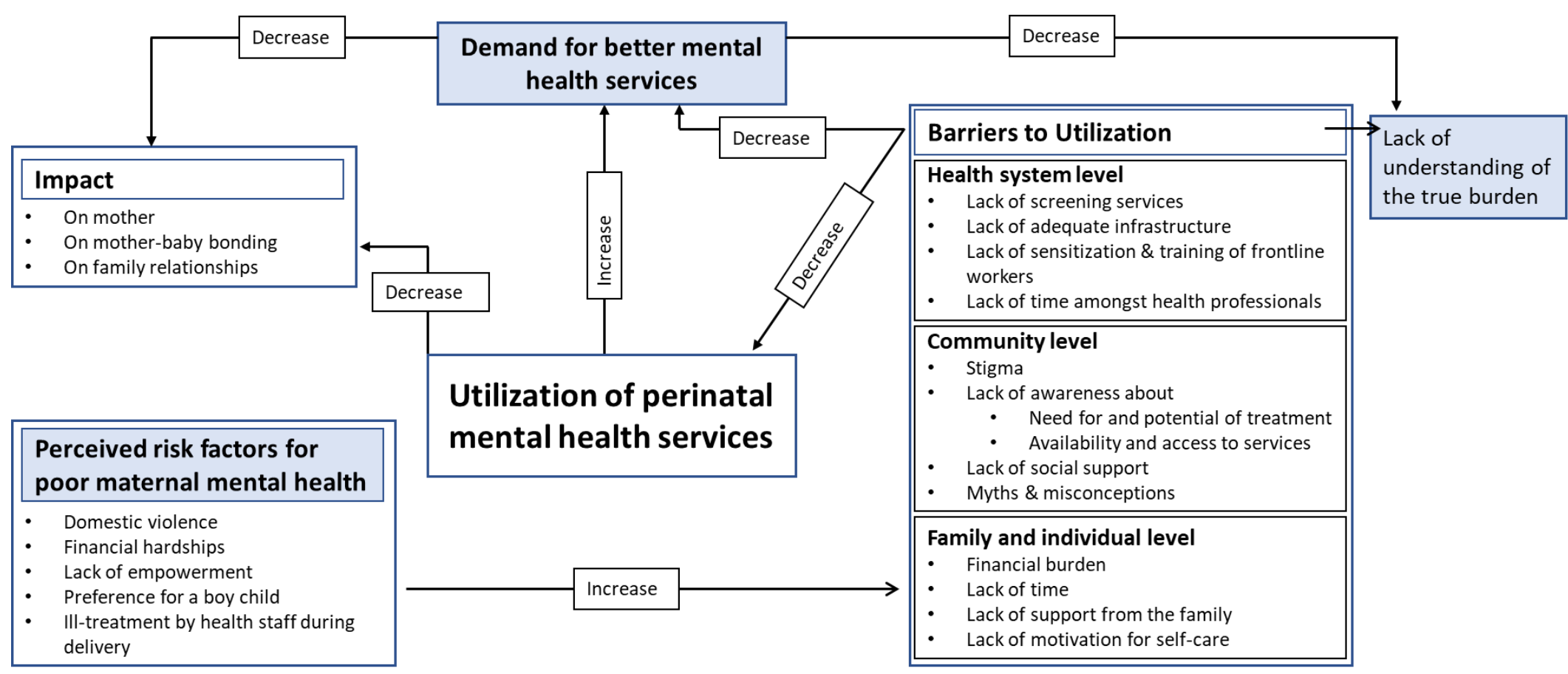


771 Figure 2: Recommended model to integrate perinatal mental health in primary care settings in Karnataka

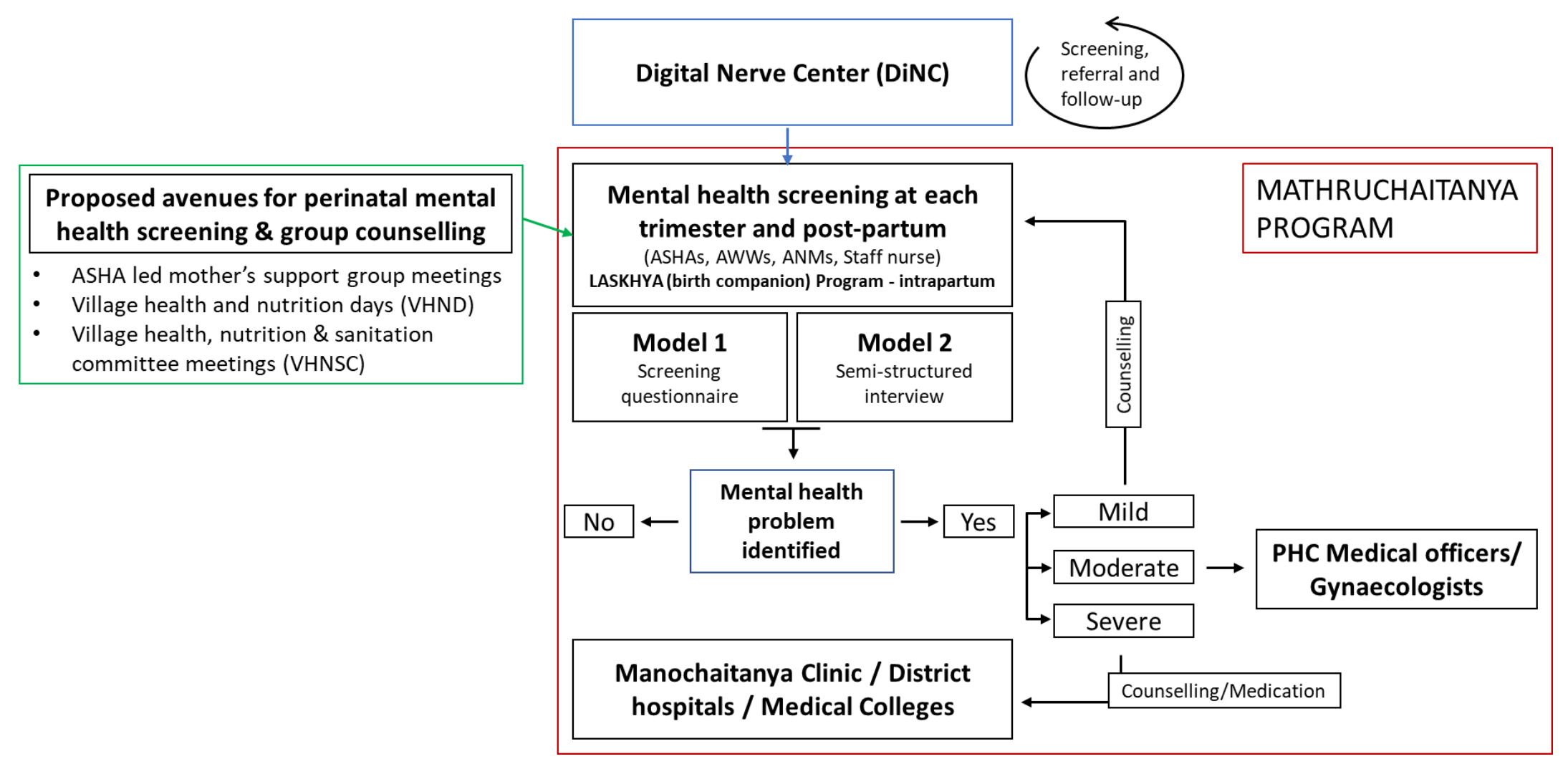




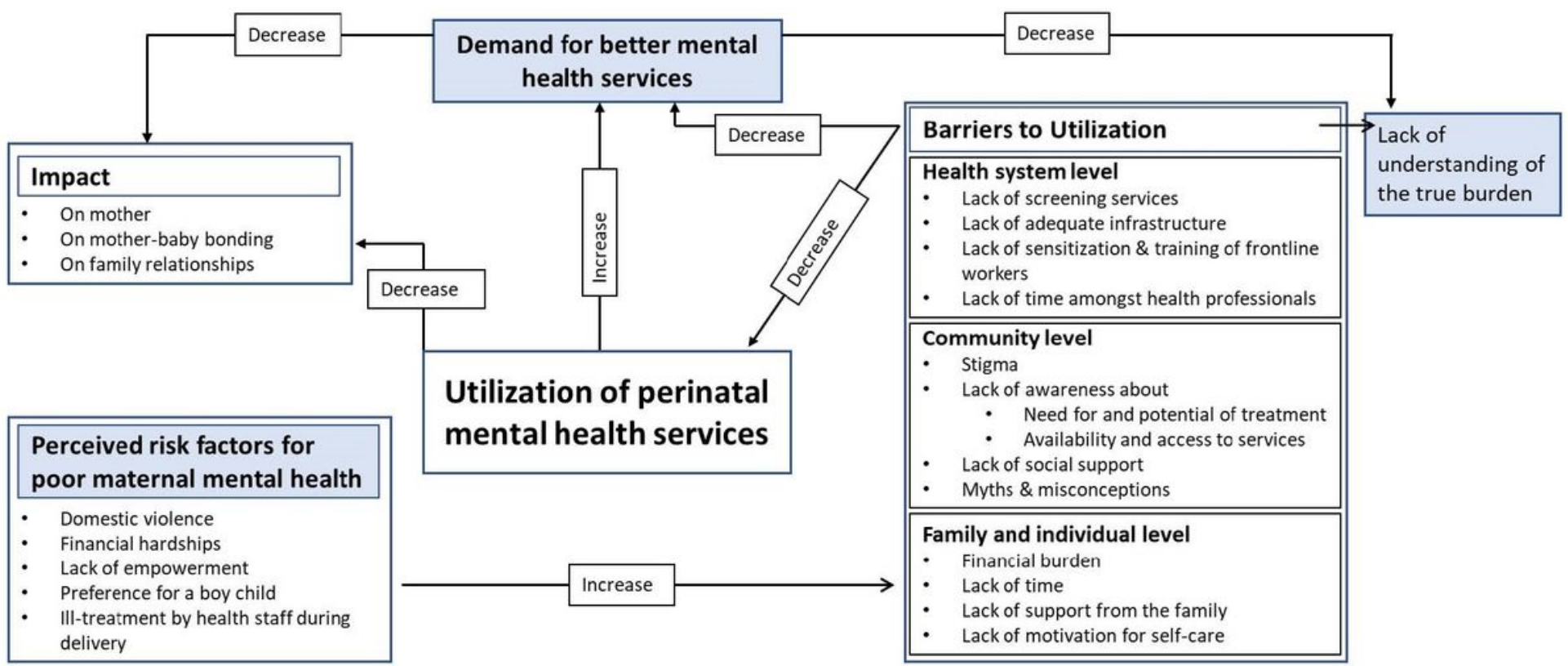

\section{Figure 1}

Framework to describe the various levels at which barriers to maternal mental health service utilization operate, their interaction with perceived causes of poor perinatal mental health, and its impact on the mother, child, and the family

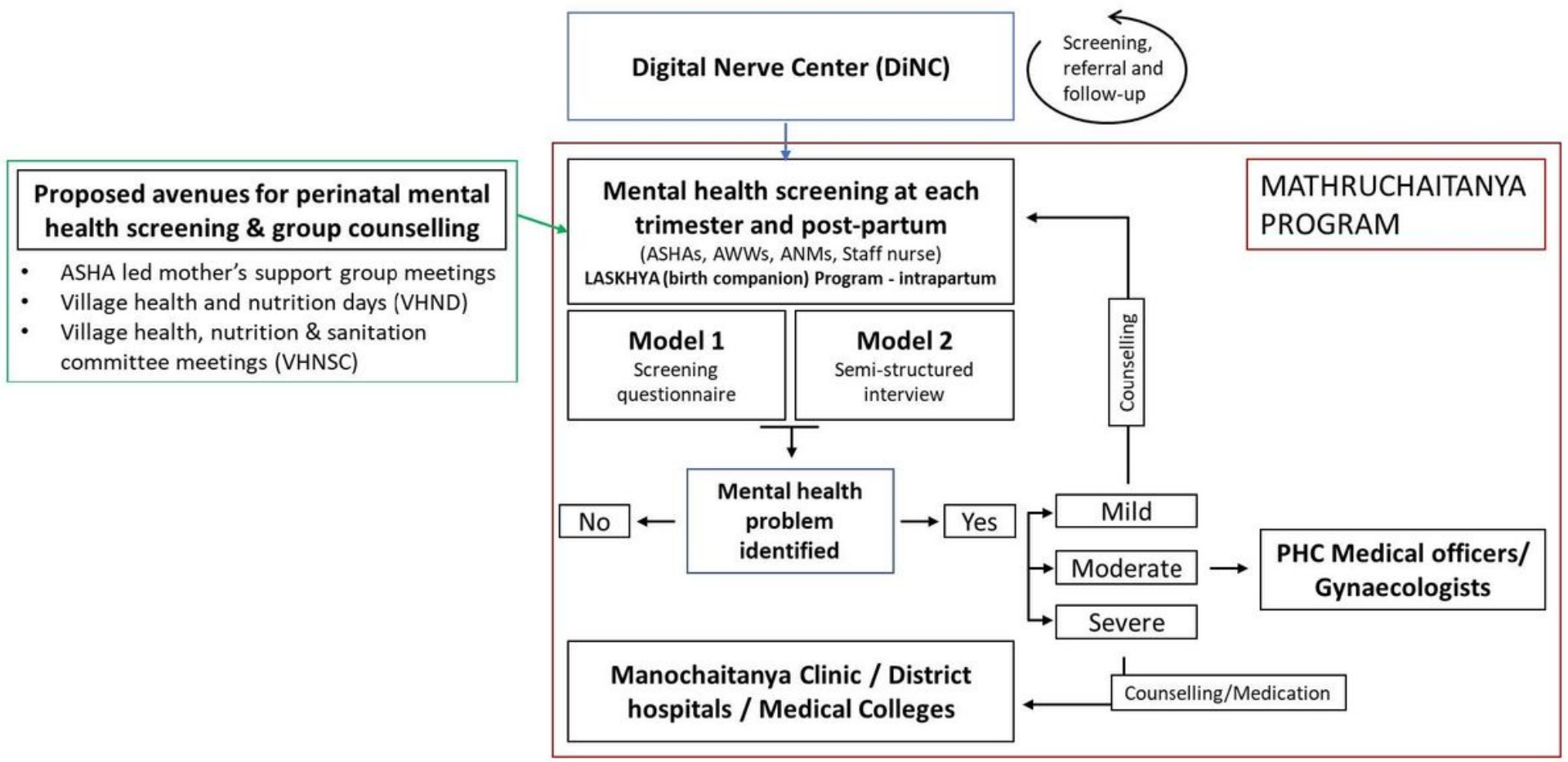

Figure 2 